University of St. Thomas, Minnesota

UST Research Online

2013

\title{
If Only I had the Time! The Impact of Time Salience on Consumers' Evaluations of Product Offers
}

David L. Alexander

University of St. Thomas, Minnesota, dlalexander@stthomas.edu

Aaron M. Sackett

University of St. Thomas, Minnesota, sackett@stthomas.edu

Follow this and additional works at: https://ir.stthomas.edu/ocbmktgpub

Part of the Marketing Commons

This Article is brought to you for free and open access by the Marketing at UST Research Online. It has been accepted for inclusion in Marketing Faculty Publications by an authorized administrator of UST Research Online. For more information, please contact asle4660@stthomas.edu. 


\title{
If only I had the time! The impact of time salience on consumers' evaluations of product offers
}

\author{
DAVID L. ALEXANDER* ${ }^{*}$ and AARON M. SACKETT \\ Opus College of Business, University of St. Thomas, Minneapolis, MN 55403-2005, USA
}

\begin{abstract}
We explore consumers' consideration of their time budgets when evaluating product offers in a context in which we expect those budgets are most easily ignored - product giveaways. Across three studies, we manipulate the salience of time for participants considering free seminars (Study 1a) and free vacations (Studies $1 \mathrm{~b}$ and 2) to be received in the near or distant future. Beginning with Study 1, we demonstrate that when time is made salient to them, consumers consider slack in their time budgets when evaluating near-future but not distant-future product giveaways. Otherwise, consumers appear to largely ignore time budget slack when evaluating free offers. In Study 2, we replicate these basic effects while providing evidence that consumers' consider slack in their time budgets at the point they commit to a giveaway rather than at the point when they will receive the product. We discuss these findings in terms of both their theoretical and marketing implications. Copyright (C) 2013 John Wiley \& Sons, Ltd.
\end{abstract}

\section{INTRODUCTION}

People love getting a deal. But even the best deal is no deal if one does not have the time to take advantage of it. For example, people love Ben \& Jerry's annual Free Cone Day, but not everyone who wants a free cone has the time to stand in the long lines that form at the stores (e.g., James, 2012). We wonder whether not being able to participate in Free Cone Day affects consumers' evaluations of Ben \& Jerry's ice cream. That is, when evaluating a product offer, do consumers consider the time they will have to invest and the slack they will need in their time budgets to take advantage of that offer?

We explore consumers' consideration of their time budgets when evaluating product offers by looking at situations in which we expect time costs and budgets are most easily ignored-product giveaways. Recent evidence suggests that "free" (a zero price) is special, with the potential to generate positive affect in consumers (Shampanier et al., 2007). With this in mind, one might expect that consumers focus on the zero price while neglecting additional costs that might be incurred. Direct response marketers appear to believe this, because they regularly sweeten their offers by throwing in a second product for free if a consumer simply pays an additional processing and handling charge. However, consumers treat time and money differently (Leclerc et al., 1995), so perhaps time costs and budgets are not easily neglected.

We begin by examining conditions in which consumers are relatively sensitive or insensitive to time budget slack when evaluating a product giveaway. We review prior literature on the nature of a zero price with an emphasis on its effect on consumers' evaluation of the product being given away. We then consider consumers' perceptions of slack in their time budgets and develop hypotheses regarding how those perceptions

\footnotetext{
* Correspondence to: David L. Alexander, Opus College of Business, University of St. Thomas, TMH 443, 1000 LaSalle Ave, Minneapolis, MN 55403-2005, USA.

E-mail: dlalexander@stthomas.edu
}

affect evaluations of the products being given away. We test our hypotheses across two studies by manipulating the salience of time for those considering free seminars (Study 1a) and free vacations (Studies $1 \mathrm{~b}$ and 2 ) to be received in the near or distant future. We find that when their current, but not future, time budgets are salient, consumers' time budgets affect product evaluations.

\section{The nature of a zero price}

Consumers are offered a wide variety of free products, although free is often not really free. Offering consumers the chance to "buy one, get one free" is equivalent to offering them half-off for purchasing two. Over-the-air broadcast television and many Internet media sources offer free content but at the cost of viewers' time and attention to commercial messages. Anderson (2009) argued that the Internet, by simplifying the implementation of cross-subsidies, has made free an increasingly viable business model on its own. He identified three free business models: direct cross-subsidies, three-party markets, and "freemium." Direct cross-subsidies incorporate the cost of the free product in the price paid for a related product (e.g., the cost of Apple Store Genius Bar tech support is embedded in the price charged for Apple products). Three-party markets use payments by one customer class to subsidize another class (e.g., Anderson offered his book for free in the UK by lining up a sponsor who bore the costs for readers). Freemium uses payments by some customers to subsidize other customers (e.g., Flickr provides a basic photo-sharing service for free while charging a fee for more functionality and greater access).

Of course, giving something away for free may have its drawbacks even if the cross-subsidies involved should prove profitable. For example, presenting a product as free may lead consumers to make negative inferences about its quality (Raghubir, 2004; Kamins et al., 2009). Subsequently, consumers may be unwilling to pay for the product in the future. That said, there is strong evidence that a zero price has special influence. Chandran and Morwitz (2006) find that monetary promotions are more likely to be processed relative 
to the original product price than are free promotions. They propose that free promotions are processed separately and are more salient, making it less likely that inferences about quality will decrease purchase intent.

Furthermore, research by Shampanier et al. (2007) shows that choices involving a free product are best explained by a model that treats zero price as a special circumstance. They find that free offers (devoid of a monetary downside) evoke higher positive affect in consumers who then use this affect as information in their decision making (see also Schwartz and Clore, 1983; Clore et al., 2001). Of course, that excitement about gaining something for free might boomerang, becoming frustration if constraints on a consumer's time budget are sufficient to prevent participation in the product giveaway - if, that is, consumers consider their time budgets.

\section{Perceiving time budget constraints}

A "time budget" is conceptualized here as consumers' own sense of the quantity of time resources they have available and how they plan to allocate those resources. A constrained time budget is one where few time resources are available, because planned time allocations are difficult to change (e.g., a professor's teaching and meeting schedule on a given day is set externally and so constrains his or her time budget). Time, as a resource, is like money except that it lacks fungibility, or substitutability; one can borrow money but not time to take advantage of a current product offer. Leclerc et al. (1995) proposed that this lack of fungibility is at the heart of why people treat time and money differently. Zauberman and Lynch (2005) find people believe their time is more constrained than their money in the present and that they will have more slack in their time budgets in the future than in the present. They posit that people anticipate having more flexibility in scheduling in the future and thus more available time. They also find less change in perceptions of money resource slack in the near versus distant future, positing that financial flexibility does not typically change between the present and the future.

We expect that, because of the strong affective reaction consumers have to free offers (Shampanier et al., 2007), they tend to neglect their time budget when evaluating a product giveaway-unless that budget is salient. When time budgets are made salient, evaluations of a product giveaway likely suffer when consumers perceive those budgets to be constrained (making it difficult or impossible to take advantage of the product giveaway). Lower evaluations of the product offers are likely reflected in lower evaluations of the products on offer. We investigate these expectations by developing and testing formal hypotheses across two studies.

\section{STUDY 1}

As consumers evaluate product giveaways, we expect that they focus on the money "saved" if the offer is accepted. This focus on money is our baseline, and we contrast evaluations of the product being given away when time is salient against this baseline. We begin by considering offers whose event time horizon (defined as when the time costs would be incurred) is the near future, as that is when people feel most time-constrained (Zauberman and Lynch, 2005). When money is salient, money budget constraints are not likely perceived, and the specialness of free (Shampanier et al., 2007) can dominate product evaluations. When time is salient, on the other hand, consumers may perceive constraints on their time that make it difficult or impossible to accrue the benefits of the product offer. The negative affect (e.g., frustration and disappointment) resulting from evaluation of the offer leads to lower evaluations of the product being given away. Formally, we propose the following:

H1: When a free product offer's event time horizon is the near future, product evaluation will be more positive when money is salient than when time is salient.

As a free product offer's event time horizon lengthens from the near to distant future, the evaluation of the product offer should change as perceptions of time budget constraints and construals of the offer change. People perceive more time budget slack in the distant versus near future (Zauberman and Lynch, 2005). When evaluating an offer of a free vacation to be taken in the distant future, consumers are less likely to perceive time budget constraints that would keep them from taking advantage of the product giveaway. Thus, when time is salient, lengthening the event time horizon on a free vacation offer is expected to improve consumers' evaluations of the offer because time budget perceptions do not result in negative affect.

In the baseline condition in which time is not salient, on the other hand, lengthening the event time horizon should influence the level of positive affect resulting from a zero price. Specifically, a distant-future event time horizon should lead to more abstract construals of the offer (Liberman and Trope, 1998; Trope et al., 2007), with less emphasis on the zero price, making it less visceral and attenuating the experienced positive affect. When money is salient, lengthening the event time horizon for a free vacation is expected to lower consumers' evaluations of the offer because there is less positive affect influencing those evaluations. Combining these different effects of time slack and product construal, we propose the following:

H2: The effect of lengthening a free product offer's event time horizon on free product evaluations is moderated by resource salience:

(a) Free product evaluations improve when time is salient.

(b) Free product evaluations decline when money is salient.

We conducted two studies to test our hypotheses. In Study 1a, we asked participants to evaluate a free negotiation seminar and manipulated resource salience supraliminally. In Study 1b, we asked participants to evaluate hotels offered as part of a free vacation and manipulated resource salience within the offer description.

\section{Study 1a: Evaluating a free negotiation seminar Participants and procedure \\ One hundred forty-three undergraduate students from a private American university participated for partial credit toward a lab requirement in their introductory marketing course during their}


spring semester. Participants were randomly assigned to an experimental condition (time vs. money salient and near vs. distant future event time horizon). The survey was administered online as part of a marketing research labs session and completed at the participant's convenience.

Participants completed two studies presented as unrelated to each other. The first study served to prime participants for either money or time salience. Participants were told that we were interested in how students at the university spent their time or money outside of school. Participants were presented with a list of activities (e.g., shopping at the school bookstore, eating at a campus cafeteria, and shopping online) and asked to list either how much time or how much money they had spent on each activity per week during the current semester.

After completing this priming task, participants were told that the researchers were working with a national marketing promotions company to develop a better understanding of young adults at US colleges and universities. The company was said to work with major learning-and-experience seminar providers to offer free weekend seminars in an effort to build brand awareness and loyalty among this highly valued market segment. Participants were told that excitement surrounding the promotion would be maximized by extending offers either a few days or a few months in advance and that participants must contact the company to accept the offer by the following day or a few weeks before the seminar depending on condition.

Participants were told that we wanted their help in evaluating some of the seminar offerings being considered for an upcoming promotion. They were told to imagine that they are offered an exciting, free 2-day weekend seminar next week or next fall and that they must make their choice either tomorrow evening or in September, depending on condition. To reinforce the manipulation, participants were told to type "I'm headed to a free seminar next week (Fall)! I'll choose my seminar tomorrow (in September)" in a text box at the bottom of the survey page labeled "Initial Thoughts."

Participants were then shown a seminar titled "Effective Negotiating," which had these descriptions:

Gain an advantage in your job search by having a coach on your side. This is a negotiation seminar that is practical, exciting, innovative, interactive, and fun.This is a winwin experience where you meet your peers, trade stories and experiences, and test your wits with others. And you win again when your career and "bottom-line" improve.

Participants were asked to indicate their attitudes toward the seminar on a 7-item, 7-point scale ( $\alpha=0.94$, derived from Bruner and Hensel, 1992) [Superior/Inferior(r); Boring/Fun; Bad/Good; Favorable/Unfavorable(r); Exceptional/Common (r); Negative/Positive; Like/Dislike(r)].

\section{Results}

Participants' responses to the attitude scale items were averaged to create an attitude score for the seminar. A $2 \times 2$ analysis of variance $($ ANOVA) $[$ attitude $=f($ resource salience, event time horizon, resource salience $\times$ event time horizon)] supplemented with planned contrasts found support for hypotheses 1 and 2 . Figure 1 illustrates our findings. Supporting H1, a planned contrast showed that when event time horizon was near, the seminar evaluations were significantly higher when money $\left(M_{\mathrm{nm}}=5.6\right)$ versus time $\left(M_{\mathrm{nt}}=4.9\right)$ was salient $(F(1$, $139)=4.84, p=0.03$ ). Supporting H2, the effect of a lengthening event time horizon was moderated by resource salience $(F(1,139)=9.97, p=0.002)$. Planned contrasts revealed that when the event horizon was lengthened from the near future to distant future, the seminar evaluations became significantly lower when money was salient $\left(M_{\mathrm{nm}}=5.6\right.$ vs. $\left.M_{\mathrm{dm}}=4.8 ; F(1,139)=7.4, p=0.007\right)$ and marginally higher when time was salient $\left(M_{\mathrm{nt}}=4.9\right.$ vs. $M_{\mathrm{dt}}=5.4 ; \quad F(1$, 139) $=3.00, p=0.085$ ).

\section{Study 1b: Evaluating free hotel rooms \\ Participants and procedure}

Thirty-nine undergraduate students from a private American university participated for partial credit toward a lab requirement in their introductory marketing course during their spring semester. Participants were randomly assigned to an experimental condition (time vs. money salient, and near-future vs. distant-future event time horizon). The survey was administered online and completed at participants' convenience.

Participants read that the researchers were working with a national marketing promotions company to better understand the travel and vacation preferences of young adults at US colleges and universities. The company was said to work with major hotel and resort operators to offer short, complimentary vacations in an effort to build brand awareness and loyalty among this highly valued market segment. Participants were told that extending offers either a few days or a few months in advance maximized excitement about the promotion, depending on condition. To manipulate time or money salience, participants then read that to defray some of the promotional costs (and to increase offer recipients' perception of the value of the vacation), offer recipients have to make a small investment of money or time to cover applicable taxes and government fees depending on condition. Participants were told that offer recipients are given a set of hotels to choose from with room descriptions and the amount of money or time (in the form of listening to hotel marketing pitches) they would pay to cover the taxes and fees for that room. Recipients would choose their hotel and pay by either the following day or a few weeks before their fall departure.

Participants were told that the researchers wanted their help in evaluating some of the hotel offerings being considered for an upcoming promotion. They were asked to imagine that they were offered a complimentary 3-day, 2-night vacation in the Florida Keys, including airfare, either next weekend or next fall depending on condition. They would have to make their hotel choice and pay the required money or time by either tomorrow evening or in September. To reinforce the manipulations, participants were then told to type "I'm headed to Florida next weekend (Fall)! I'll choose my hotel and pay the taxes and fees (attend the marketing pitches) tomorrow (in September)" in a text box labeled Initial Thoughts. They were then told that they would see individual hotel descriptions and be asked to rate the attractiveness of each hotel.

To reduce noise due to idiosyncratic preferences for amenities and features, we asked each participant to evaluate 


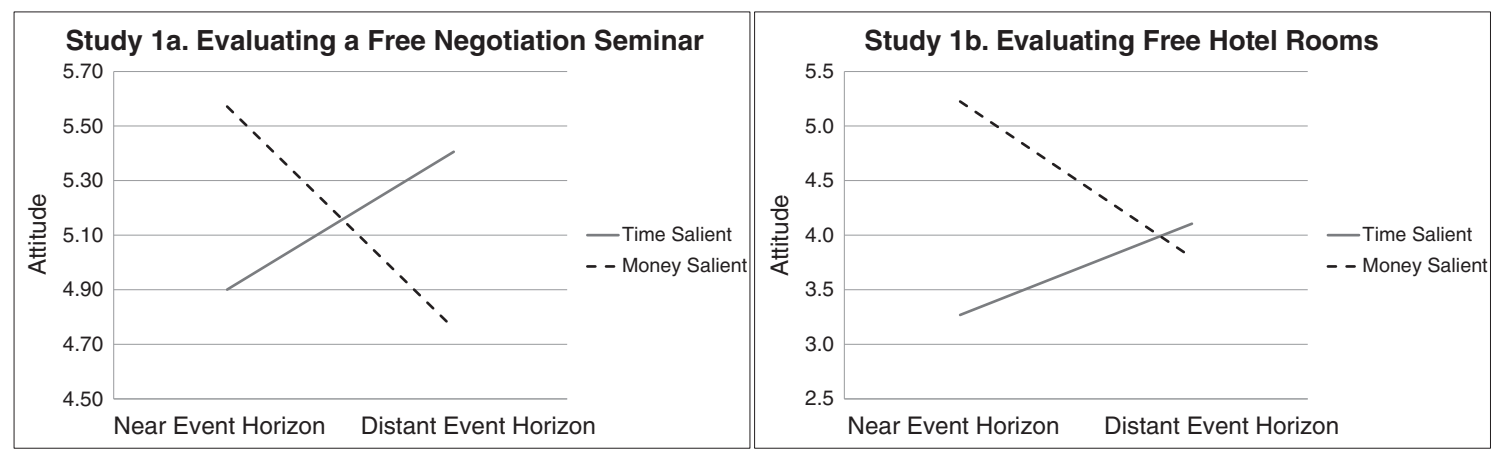

Figure 1. Attitudes change as a function of event time horizon. The effect of lengthening event time horizon on attitude is moderated by resource salience. Attitudes decline when money is salient and increase when time is salient.

two different hotels. Hotel Et was described as a beautiful beachfront resort where patrons would stay in a casually sophisticated bungalow but that the hotel was addressing its security issues. Hotel One was described as an exciting, exotic locale where patrons would enjoy the lovely spa complex overlooking peaceful gardens but that the hotel features limited cell phone reception and Internet access. Participants indicated their attitudes toward each hotel on the scale used in Study 1a $(\alpha=0.96)$.

\section{Results}

Participants' responses to the attitude scale items for a hotel were averaged to create an attitude score for that hotel. A $2 \times 2$ full-factorial between subjects ANOVA controlling for repeated responses from participants [attitude $=f$ (resource salience, event time horizon, resource salience $\times$ event time horizon, participant dummy)] supplemented with planned contrasts found support for our hypotheses. Figure 1 illustrates our findings. Supporting H1, a planned contrast showed that when the event time horizon was near, offer evaluations were significantly higher when money $\left(M_{\mathrm{nm}}=\right.$ $5.2)$ versus time $\left(M_{\mathrm{nt}}=3.3\right)$ resources were salient $(F(1$, $35)=12.53, p=0.001)$. Supporting $\mathrm{H} 2$, the effect of event time horizon was moderated by resource salience $(F(1$, $35)=9.48, p=0.004)$. Planned contrasts revealed that when the event horizon was lengthened from the near future to distant future, the hotel evaluations became significantly lower when money was salient $\left(M_{\mathrm{nm}}=5.2\right.$ vs. $M_{\mathrm{dm}}=3.8 ; F(1$, $35)=6.43, p=0.016)$ and marginally higher when time was salient $\left(M_{\mathrm{nt}}=3.3\right.$ vs. $\left.M_{\mathrm{dt}}=4.1 ; F(1,35)=3.13, p=0.086\right)$.

\section{Study 1 discussion}

The results of Studies 1a and $1 \mathrm{~b}$ provide evidence that consumers will indeed consider their time budgets when evaluating product offers, even offers for free products (and those just marketed as free). People likely perceive that they have little slack in their time budgets in the near term (Zauberman and Lynch, 2005), so they devalue a product that would be difficult (or impossible) to fit into their busy schedule. As consumers perceive greater slack in time budgets in the future (Zauberman and Lynch, 2005), consumers can more easily accommodate the time required by a product, enhancing their evaluation of that product. The results also suggest that when time budgets are not salient, a free product may gain a boost in evaluations as a result of the positive affect associated with a zero price (Shampanier et al., 2007), but this boost declines with time as one's thoughts become more abstract (Trope and Liberman, 2003) and that positive affect is attenuated.

To provide broader evidence of our hypothesized effects, Studies $1 \mathrm{a}$ and $1 \mathrm{~b}$ differed in the product that participants were asked to evaluate and the manner in which time versus money salience was manipulated. The negotiation seminar offered in Study 1a is a relatively utilitarian product, whereas the hotels offered in Study $1 \mathrm{~b}$ are relatively hedonic products. Study 1a manipulated resource salience (time vs. money) using a supraliminal priming procedure that preceded the free seminar offer. Study $1 \mathrm{~b}$, on the other hand, used the offer's restrictions to make time or money salient. Here, we used a tactic common among marketers of timeshare properties-offering consumers a free vacation with an incidental side cost of either time or money. Importantly, we find that consumers' consideration of their time budgets can be triggered both by unrelated situational factors and by marketer actions.

\section{STUDY 2}

Marketers frequently make offers for products that will be available in the distant future but that can be pre-purchased today. Amazon.com, for example, uses discounts to encourage consumers to pre-order DVDs for popular films months before those DVDs are released. In Study 2, we explore how early commitment to a product giveaway affects consumers' consideration of their time budgets. We expect that requiring consumers to make an early commitment to a product giveaway alters their perception of the event time horizon for that giveaway. That is, when time is salient, having to make a commitment of time resources now makes one's near-term time budget constraints salient and changes the perceived event time horizon to include the near future. As a result, the greater perceived time budget constraints in the present (Zauberman and Lynch, 2005) are considered when the commitment point is in the near future, even though the actual event time horizon is in the distant future. Formally, we propose the following: 
H3: When time is salient, product evaluation will be less positive when a free product offer's commitment point is the near future than the distant future.

\section{Participants and procedure}

Seventy-seven undergraduate students from a private American university participated for partial credit toward a lab requirement in their introductory marketing course. Participants were randomly assigned to an experimental condition (time vs. money salient and near-near vs. near-distant vs. distant-distant commitment-event time horizon). The survey was administered online and taken at the participant's convenience.

The procedure for Study 2 was identical to that in Study $1 b$, with a few exceptions. In Study 2, a new experimental condition was added in which participants were told that vacations are offered a few months in advance and that recipients must choose their hotel and pay the taxes (in time or money) by the next day (the near commitment-distant event horizon condition). The manipulation reinforcement for this new condition required that participants type "I'm headed to Florida next Fall! I'll choose my hotel and pay the taxes and fees (attend the marketing pitches) tomorrow" in a text box labeled Initial Thoughts. Participants evaluated a single hotel (Hotel Uno) described as a unique Florida Keys experience where your room is a comfortable, windowless interior room and there is a continuous airport shuttle service for the 10 minute trip to/from the hotel.

\section{Results}

Participants' responses to the attitude scale items were averaged to create an attitude score for the hotel $(\alpha=0.96)$. A $2 \times 3$ ANOVA [attitude $=f$ (resource salience, commitment-event time horizon, resource salience $\times$ commitmentevent time horizon)] was performed, and planned contrasts were used to test the hypotheses. Consistent with H3, a planned contrast revealed that when time was salient, evaluations differed as a function of whether commitment time horizon was in the near versus distant future $\left(M_{\mathrm{NNt}}=2.2\right.$ and $M_{\mathrm{NDt}}=2.4$ vs. $\left.M_{\mathrm{DDt}}=3.3 ; F(1,71)=6.07, p=0.016\right)$. Providing additional support for $\mathrm{H} 3$, evaluations made in conditions in which commitment was near did not differ as a function of whether event time horizon was in the near versus distant future
$\left(M_{\mathrm{NNt}}=2.2\right.$ vs. $\left.M_{\mathrm{NDt}}=2.4 ; F(1,71)=0.13, p=0.722\right)$. Figure 2 illustrates our findings.

The results of Study 2 offer further support for $\mathrm{H} 1$ and $\mathrm{H} 2$. Supporting H1, a planned contrast found that evaluations when both commitment and event horizon were near were significantly higher when money was salient versus when time was salient $\left(M_{\mathrm{NNm}}=3.4\right.$ vs. $M_{\mathrm{NNt}}=2.2 ; \quad F(1,71)=4.52$, $p=0.037)$. Supporting H2a, when time was salient, a planned contrast found that participants made significantly higher evaluations if both commitment and event horizon were distant than if both were near $\left(M_{\mathrm{DDt}}=3.3\right.$ vs. $M_{\mathrm{NNt}}=2.2 ; F(1$, $71)=4.79, p=0.032$ ). Consistent with $\mathrm{H} 2 \mathrm{~b}$, a planned contrast found a marginally significant difference in evaluations in the near versus distant future $\left(M_{\mathrm{NNm}}=3.4\right.$ vs. $M_{\mathrm{DDm}}=2.4 ; F(1$, $71)=3.36, p=0.071$ ) when money was salient.

Our theory makes no predictions about the effect of lengthening the commitment point from the near to the distant future when money is salient. However, in the interest of methodological completeness, we included a condition involving near commitment and a distant event time horizon when money was salient. Planned contrasts found no significant differences between evaluations made in this condition and (i) evaluations made in the conditions in which commitment was near and money was salient $\left(M_{\mathrm{NDm}}=2.8 \mathrm{vs}\right.$. $M_{\mathrm{NNm}}=3.4 ; F(1,71)=1.00, p=0.32$ ) or (ii) evaluations made in the conditions in which event horizon was far and money was salient $\left(M_{\mathrm{NDm}}=2.8\right.$ vs. $M_{\mathrm{DDm}}=2.4 ; \quad F(1$, $71)=0.52, p=0.47)$.

\section{Discussion}

Study 2 replicated the results of Study 1 showing that consumers evaluate a product given away in the near future less positively when time is salient but those evaluations become more positive as the event time horizon lengthens. Furthermore, Study 2 provides evidence supporting our expectation that, when time is salient, requiring consumers to commit to a distant-future giveaway now changes their perception of the giveaway's event time horizon. Asking consumers to reserve time resources immediately makes their current time budget constraints salient and leads to less positive evaluations of the product given away. This is true even when the actual event horizon is in the distant future.

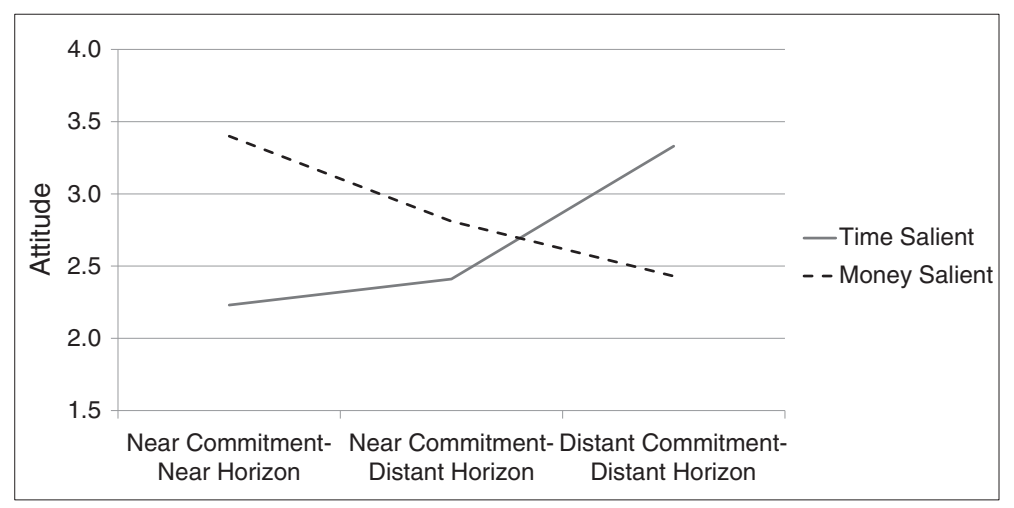

Figure 2. Time of commitment, rather than time of event, drives evaluations when time is salient. Data from conditions in which money was salient are displayed for comparison. 


\section{GENERAL DISCUSSION}

Our objective in the current project was to examine whether and when consumers considered their time budgets when evaluating product offers-specifically product giveaways. We used product giveaways because they allowed us to control for money costs and the salience of time. Using product giveaways also provided a more conservative test of our expectations because the positive affect they have been shown to generate might be expected to overwhelm consideration of time budgets. Across our studies, we found that consumers do appear to consider their time budgets when evaluating free product offers, but only when time is salient, and those evaluations affect evaluations of the product being given away. We found that free product evaluations were lowest when consumers' near-future time budgets were salient. As consumers' focus shifted from their near-future to the distant-future time budgets, free product evaluations improved, presumably as consumers perceived fewer constraints on the their time budgets (Zauberman and Lynch, 2005).

\section{Theoretical implications}

The present results highlight consumers' consideration of time costs and time budgets that are a nearly ubiquitous feature of real consumer contexts but are vastly understudied. Our findings suggest that, like money, time is a resource that consumers will consider (at least under certain circumstances) when evaluating products. However, the results of Study 2 also suggest that consumers' responses to time-based and money-based costs may differ in theoretically important and interesting ways. Consistent with Leclerc et al. (1995), we would argue that time costs warrant greater scholarly attention, as they can have meaningful effects on consumer judgments that are likely distinct from those of monetary costs.

Additionally, our findings offer possible boundary conditions to past research suggesting that free product offers are uniquely appealing because of affective processes (Shampanier et al., 2007). Specifically, our data suggest that this unique appeal may be attenuated for free products that involve time costs when consumers' near-term time constraints are salient. It is possible that, under such conditions, the positive affective response to zero price is suppressed. Alternatively, and perhaps more plausibly, the positive affective reaction to zero price might persist whereas a second affective force-negative affect produced by feelings of time poverty-may serve to counterbalance consumers' attitudes toward the free product.

\section{Marketing implications}

This research has interesting implications for both marketers and market researchers. For decades, marketers have clearly recognized the unique appeal of free offers, despite not fully understanding the reasons behind it. They have bombarded consumers with a myriad of promotions centered on free giveaways. With this in mind, the promotional scenarios we presented in Studies $1 \mathrm{~b}$ and 2 were deliberately designed to reflect one common marketing practice-offering free vacations with only the requirement that consumers pay minimal fees and/or attend time-share sales pitches. In many such marketing strategies, the offer's event time horizon is constrained to the relatively near future. In light of the present data, it seems that marketers may unintentionally undermine the effectiveness of such promotions if they choose to emphasize their minimal time costs ("all you need to do is attend a short 90-minute presentation!") rather than their minimal monetary costs ("all you need to pay for is the local taxes on the value of the stay!"). Even though both of these potential costs may indeed seem small to consumers, emphasizing the time costs rather than monetary costs may focus consumers' attention toward the likely fact that they currently feel very little time slack ("I don't have time for a vacation right now!") and away from the positive affect that a free offer would ordinarily evoke.

The present research also has clear implications for market researchers studying demand for products requiring time investments whether free or not. Estimates of demand for these types of products must be adjusted for the effect of consumers' consideration of their time budgets. We find the likely perception that one has more slack in their time resources in the distant rather than near future (Zauberman and Lynch, 2005) leads to more positive product evaluations when the product's event time horizon is the distant future, likely causing potential consumers to overstate their purchase intentions. These effects are distinct from the effects on purchase intentions and follow-through that prior research has found for changing product construals across time (Alexander et al., 2008).

\section{Future research}

The present data provide new evidence for a potentially important interaction effect between resource salience and event time horizon on consumers' evaluations of free promotions. Although our findings have considerable theoretical and practical implications, they also raise new questions. One such question is whether the observed effects of time resource salience are unique to free offers. Past research suggests that our observed effects of money resource salience are indeed unique to free offers (Shampanier et al., 2007), because of a special affective response consumers have to the idea of "free." If the time resource salience effects are also due to an affective response, it seems likely that this would occur because of frustration when considering offers in the near future ("I want to take advantage of this offer but don't have the time!") and excitement when considering offers in the distant future ("What a great deal! I don't have anything planned 6 months from now!'). However, there is currently no strong theoretical argument for why this mechanism would not also apply to event time horizon differences with other desirable, non-free offers. Thus, future research is necessary to more closely examine the boundary conditions of this particular feature of our results.

Given the data obtained in the present studies, some might be tempted to conclude that evaluations for distant future offers will be higher if time resources are salient than if money resources are salient. Our theoretical premise, however, was not formulated with this particular test in mind, and the data are not conclusive on this 
matter. However, in all three studies, the mean evaluation is consistently (if non-significantly) higher in the distant condition when time resources are salient rather than money resources. We suggest that future research should be carried out to determine whether this pattern is robust, as this would certainly contribute further to our growing understanding of the relationship between resource salience, temporal distance, and consumers' judgments about free product offers.

\section{CONCLUSION}

Free promotions have a firm foothold in the modern marketing landscape, and by at least casual observation, their prevalence is only growing. Given that the unique appeal of these promotions stems from affective responses to their (zero) monetary cost (Shampanier et al., 2007), it seems only natural that emphasizing temporal side costs would be less detrimental to consumer evaluations than would emphasizing money side costs. The research we present here suggests that this is a potentially disastrous assumption for marketers to make. For free promotions available in the near future-which we suspect describes most free promotions in the current marketplace-making money salient to consumers rather than time may significantly enhance the appeal of the offer.

\section{BIOGRAPHICAL NOTES}

David L. Alexander is Assistant Professor of Marketing at the University of St. Thomas, Opus College of Business. He received his MBA and PhD in marketing at the Fuqua School of Business at Duke University. His research focuses on how an innovation's psychological newness interacts with contextual factors, such as temporal distance, to affect consumers' considerations of that innovation at each step in the innovation adoption decision process.

Aaron M. Sackett is Assistant Professor of Marketing at the University of St. Thomas, Opus College of Business. He earned his PhD in social psychology at Yale University. Broadly speaking, he is interested in issues related to judgment and decision making. His research interests include hedonic evaluation, metacognitive inferences, the psychological effects of time, prediction biases, and the relationships between goals, outcomes, and satisfaction.

\section{REFERENCES}

Alexander DL, Lynch Jr JG, Wang Q. 2008. As time goes by: Do cold feet follow warm intentions for really new versus incrementally new products? Journal of Marketing Research 45(June): 307-319.

Anderson C. 2009. Free: The Future of a Radical Price. Hyperion: New York.

Bruner II GC, Hensel PJ. 1992. \#31 Attitude toward the product/brand (semantic differential). In Marketing Scales Handbook: A Compilation of Multi-item Measures (Volume 1). American Marketing Association: Chicago; 82-92.

Chandran S, Morwitz VG. 2006. The price of 'free'-dom: Consumer sensitivity to promotions with negative contextual influences. Journal of Consumer Research 33(December): 384-392.

Clore GL, Gasper K, Garvin E. 2001. Affect as information. In Handbook of Affect and Social Cognition. Forgas JP (ed.). Lawrence Erlbaum Associates: Mahwah; 121-144.

James E. 2012. Coneheads score free ice cream. The Orange County Register (April 3, 2012): accessed online March 25, 2013 at www.ocregister.com/articles/jerry-347615-year-day.html.

Kamins MA, Folkes VS, Fedorikhin A. 2009. Promotional bundles and consumers' price judgments: When the best things in life are not free. Journal of Consumer Research 36(December): 660-670.

Leclerc F, Schmitt BH, Dubé L. 1995. Waiting time and decision making: Is time like money? Journal of Consumer Research 22(June): 110-119.

Liberman N, Trope Y. 1998. The role of feasibility and desirability considerations in near and distant future decisions: A test of temporal construal theory. Journal of Personality and Social Psychology 75(1): 5-18.

Raghubir P 2004. Free gift with purchase: Promoting or discounting the brand? Journal of Consumer Psychology 14(1\&2): 181-186.

Schwartz N, Clore GL. 1983. Mood, misattribution, and judgments of well-being: Informative and directive functions of affective states. Journal of Personality and Social Psychology 45(3): $513-523$

Shampanier K, Mazar N, Ariely D. 2007. Zero as a special price: The true value of free products. Marketing Science 26(November-December): 742-757.

Trope Y, Liberman N. 2003. Temporal construal. Psychological Review 110(3): 403-421.

Trope Y, Liberman N, Wakslak C. 2007. Construal levels and psychological distance: Effects on representation, prediction, evaluation, and behavior. Journal of Consumer Psychology 17 (2): 83-95.

Zauberman G, Lynch Jr JG. 2005. Resource slack and propensity to discount delayed investments of time versus money. Journal of Experimental Psychology. General 134(1): 23-37. 